\title{
CONTAR EL EXILIO. Relatos sobre fronteras en la frontera
}

Nora Ricaud ${ }^{*}$

Universidad Nacional de la Patagonia Austral

1.

Este escrito aborda el tema de los modos de la escritura autobiográfica y además habla sobre las formas del exilio. Más particularmente, se refiere a los modos en que ambos tópicos se concretan en dos textos de la escritora argentina Tununa Mercado: En estado de memoria y Yo nunca te prometí la eternidad.

Ambos libros piden ser leídos no como textos cerrados, sino como un continuum, en tanto la escritura los presenta enlazados en un devenir de un texto en el otro, y del contenido en la forma. Cada una de estas historias es una estación del exilio. Una, subsumida en la otra; una, parida por la otra. El relato en primera persona cuenta tanto el exilio propio como el ajeno, transitando bordes en donde el juego de espejos oblitera la posibilidad de distinguir lo propio y lo ajeno, el sí mismo y el Otro. Es por ello que lo apropiado parece ser un abordaje que eluda la estabilización del sentido y que sea capaz de hacerse cargo del carácter insaturable de la escritura de Tununa Mercado.

Jacques Derrida, como se sabe, en el intento de deconstruir las dicotomías dentro/fuera y propio/ajeno trabaja sobre lo que él denomina parergón, retomando lo que Kant llama parerga, cuando se refiere a lo accesorio, lo secundario, lo periférico. Aborda tal problemática analizando lo que tradicionalmente se ha desechado con esos rótulos: los marcos de los cuadros, los paños de las estatuas, los peristilos de edificios (La Diseminación. La verdad en pintura). Esta revalorización de lo marginal, que ocupa la mayor parte de la deconstrucción y de los estudios derridianos, quiere ser presentada en esta

\footnotetext{
Nora Ricaud es Profesora Ordinaria Asociada en Teoría Literaria. Desarrolla investigaciones sobre literatura autobiográfica producida en las últimas décadas sobre una selección de escritores de Argentina.
} 
ocasión como modo de lectura, una lectura desde los márgenes, que reivindica el carácter inestable y a la vez productivo de los textos que leemos.

Raúl Antelo, por su parte, enfatiza el sentido polémico que encierra el término frontera que por su etimología implica confrontar, esto es, no sólo comparar, sino también polemizar, obstruir. ${ }^{1}$ En este sentido, esta intervención aspira a construir una crítica que intente ver más allá del sentido establecido. Ver cómo los lindes o las fronteras pueden ser convocados en el trabajo crítico en torno a las formas de lo autobiográfico y cuando esas formas traman el relato del exilio, tal como ellos aparecen planteados en En estado de memoria y en Yo nunca te prometí la eternidad. ${ }^{2}$

El relato de la experiencia del propio exilio pone en juego una cuestión de límites, de lindes que podemos explicitar. En primer lugar, el sentido de la autobiografía, la elección de la primera persona, implica privilegiar un modo particular de narración que equivale a contar desde el borde aquello que se ubica en el borde, en tanto la situación narrada, el exilio, se presenta también como un límite. Giorgio Agamben considera al exiliado (el refugiado, el desterrado, el apátrida) como un concepto límite que viene a poner en crisis la unión entre nacimiento y soberanía, la vida natural como fuente de la soberanía, que es propia del nuevo orden del Estado. El desterrado ocupa un lugar paradójico en la relación entre la norma y la excepción que define el poder soberano. El desterrado (messo al bando le llama Agamben, siguiendo a Nancy) no sólo está excluido de la ley sino que ésta se mantiene en relación con él a-bandonándole, la ley se aplica a él bajo la forma de la suspensión. Por ello, el exiliado no está ni dentro ni fuera del ordenamiento jurídico, se sitúa más allá del ámbito de los derechos y de las penas. Las historias que nos ocupan dan cuenta del fenómeno de desbordamiento de refugiados y apátridas, por el escenario europeo y latinoamericano, en diversas circunstancias políticas, en donde es dable observar la separación del nexo nacimiento-nación en el que se fundó la soberanía popular,

\footnotetext{
${ }^{1}$ Antelo, Raúl (2008) "Lindes, límites, liminares”. Universidade Federal de Santa Catarina

${ }^{2}$ No nos interesa un enfoque generalizador en torno a cuestiones teóricas sino uno compatible con una forma de conocimiento local, que rescate las características concretas que el fenómeno adquiere en un contexto específico, en este caso, las dos narraciones de Mercado.
} 
y en donde se produce una regresión masiva al concepto de vida natural, de vida desnuda desprovista de valor político.

La perspectiva autobiográfica, entre las variadas cuestiones que plantea, se afirma sobre la singularidad de la experiencia, que por definición viene a ubicarse en un lugar de frontera. Desplazada de los lazos sociales, la narración en primera persona tiende a neutralizar lo colectivo para poner el foco en el sujeto que dice "yo". Pero el sujeto está inmerso de modo inevitable en los avatares del contexto histórico, de modo que en su discurrir establece cruces con la experiencia colectiva. Entonces, en la singularidad de lo vivido se reconstituye el lazo social. Además lo personal se proyecta en lo colectivo en tanto el autobiógrafo no escribe sólo para sí, le habla a un colectivo y las voces de ese colectivo atraviesan la propia palabra.

Por otra parte, está la cuestión de la "verdad" que estos escritos plantean en tanto la escritura autobiográfica se postula, desde una pretendida definición genérica, como un relato "verdadero" que el autor hace de sí mismo. Narrar el propio exilio habilita entonces la cuestión del valor testimonial que este tipo de escrito encierra. Más allá del discutible valor de prueba jurídica que lo testimoniado pudiera tener en estos textos autobiográficos, podríamos decir que allí la palabra adquiere una especie de derecho suplementario a la credibilidad, que no deja de resultar paradójico: la palabra propia, en tanto perspectiva única y singular, promueve la suspensión de la atribución de verdad o de prueba absoluta. Representa en última instancia, en tanto versión única, un enigma irreductible. Pero al mismo tiempo, y por la misma razón, encierra una "verdad" imposible de desechar. Palabra que se acredita con la autoridad de lo vivido y es por ello digna de fe. Palabra que se engendra, que toma cuerpo, en los avatares del propio cuerpo. Estos textos de Mercado, que hablan del exilio desde lo vivido, no se ofrecen como depositarios de la verdad o del sentido, sino que crean cierto efecto de sentido, una puesta en escena de sentidos, una puesta en escena de la escritura, en donde la experiencia del exilio se hace más elocuente.

\section{Memoria y narración. En estado de memoria}


Puesto que escribir es hacer presente una ausencia (Blanchot, 1955:27), la negatividad fundacional de la escritura, adquiere su mayor grado de tensión en la escritura de la intimidad, en el relato de la vivencia personal, que cifra su imposibilidad en la distancia que debe asumir quien escribe para ver/verse. Describir la propia experiencia, es conocer la mayor distancia. Allí, el discurso conoce la extrañeza de recuperar la propia imagen, de dar forma al yo que se quiere convertir en presencia.

"La enfermedad", primer relato de En estado de memoria ${ }^{3}$ puede ser entendido como el modelo de la puesta en marcha de la escritura del yo, en la que el gesto autobiográfico encuentra el modo de hacerse comunicable, al mismo tiempo que establece las condiciones de lectura. Se abre con una evocación de Cindal, personaje emblemático que encarna la exasperación de la angustia: En la antesala del consultorio del psiquiatra, el hombre irrumpe implorando ser atendido, sin turno; su estado es de extrema desesperación y sufrimiento, como lo evidencian sus gritos de dolor y el retorcimiento de su cuerpo. Sin embargo no logra conmover al psiquiatra y se retira sin haber recibido auxilio. Esa misma noche el desahuciado se ahorca.

La referencia a Cindal aparece bajo la forma de una evocación recurrente de la narradora, quien reconoce en este caso su propia situación de desamparo. Cindal es para ella el nombre paradigmático de la "enfermedad", aquella que caracteriza a los seres marcados por el desvalimiento y que se traduce en un sumiso peregrinar por diferentes formas de terapia, en busca de una cura que nunca puede satisfacerse. La voz enunciadora del relato se hace explícita en el uso de la primera persona para establecer una continuidad entre Cindal y ella. Las referencias personales habilitadas por esta vía se multiplican: "Muchas veces el nombre de Cindal fue evocado por mi"; "sus demandas y las mías"; "él parecía decidido a hacerlas oír, yo en cambio...". Hasta que la narración se instala definitivamente en los avatares del yo de la narradora. Mediante este gesto sutil Cindal se convierte en el recurso para hablar de sí misma: ella es el verdadero caso. La narración desplaza su foco desde Cindal al sujeto responsable de la narración, que viene a ocupar ahora el centro.

\footnotetext{
${ }^{3}$ Las citas se harán sobre la edición de En estado de memoria, 1998, Alción, Córdoba, Argentina
} 
La escritura introspectiva se presenta así como un "caso", bajo la metáfora de la enfermedad. El cuerpo será así la superficie privilegiada en donde se registran los efectos más hondos y devastadores del arrasamiento de la subjetividad operada por el exilio. La situación comunicativa desde la que fluye la narración es tratada como el enunciado de un paciente ante el psiquiatra. El contenido del enunciado, anclado en las formas de lo autobiográfico, es el relato de la interioridad de la autora, el estado psíquico y físico que se expresa en diversas formas de la inestabilidad, de la angustia, de la vulnerabilidad.

En la insistencia de la frase "lo que yo tenía que exponerle a ese psiquiatra virtual" se completa el modelo comunicacional con la construcción de un destinatario: en ese psiquiatra que reclama se metaforiza la figura del lector, último destinatario de su escritura. Una escritura a la que le asigna también una función, desde que viene a asumir el lugar de la terapia de psicoanálisis individual que siempre se le ha negado (en espejo con lo que le ocurre a Cindal): "No tuve entonces un tiempo individual en el que discerniera mis conflictos de una manera especializada y específica".

Por la escritura podrá indagar en los propios procesos anímicos, encontrar su propia imagen, reconocerse.

\subsection{Fenomenología del exilio}

La literatura de Tununa Mercado es en muchos sentidos un prolongado y minucioso estudio de la experiencia del exilio. En estado de memoria explora esa experiencia de modo casi fenomenológico, de eso oscuro, irracional y sin nombre que se expresa bajo la forma de la enfermedad y de la muerte, y cuyas marcas son más las de una carencia que las de un patrimonio.

El libro reúne una serie de relatos que se presentan como una constante interrogación acerca de la experiencia del exilio que la autora vivió en dos oportunidades, primero en Francia entre 1966 y 1970 y luego en México entre 1974 y 1987. Su eficacia narrativa está en el hecho de que no se centra en la anécdota, en la exposición de los acontecimientos exteriores, sino en los núcleos constitutivos de la experiencia humana del desamparo y de la carencia como 
estado humano esencial y los convierte en el impulso de su escritura, a la vez que reflexiona sobre las condiciones que hacen posible la narración.

El punto de partida del relato es la escena de Cindal, no sólo por ser primera en el orden del libro, como ya dijimos, sino porque le permite a la autora, en primer lugar, construir una imagen de sí, como sujeto que se piensa en la apelación a su doble. Según Julia Kristeva, la alienación define la condición del extranjero: ser otro. En ese sentido, la figura del doble no tiene aquí la función de representar, Cindal: signo que representa al yo enunciador, sino de mostrar, hacer aparecer en un juego de espejos, alumbrar su propia condición. En segundo lugar, la escena funciona como núcleo organizador del relato, en tanto su evocación pone en funcionamiento la memoria y con ello da cauce al relato de la propia experiencia. Resulta por lo tanto una construcción retórica destinada a fundar la escritura de la memoria.

Narrar la memoria tiene aquí el sentido que le da Walter Benjamin y que se pone a prueba en la obra de Proust, es decir no el relato de acontecimientos fijados en el recuerdo, que la memoria recoge en la escritura como evocación del pasado, sino con valor de presente vivo en tanto recuperación de datos acumulados de modo inconsciente que se construyen como memoria por el ejercicio de la escritura, a partir de acontecimientos u objetos que la estimulan. Tununa Mercado explicita este mecanismo en la referencia a los muertos queridos evocados cada vez que ejecutan las acciones a las que los tiene asociados. Si la memoria sólo es posible en el acto de escribir, se puede decir que la escritura tiene el sentido de una búsqueda, escribe para saber, para reconocerse en el ejercicio de la memoria que se despliega en escritura. La fragmentariedad, la discontinuidad de los acontecimientos, la consideración provisional de las vivencias por encima de la certeza, son el resultado de este relato en construcción, carente de una historia o argumento previo.

En otra ocasión, durante un Coloquio (Martínez_Richter,1997) la autora expresa que "la escritura no es otra cosa que memoria", pero inmediatamente descarta el sentido de memoria como espacio de lo ya muerto a la que le correspondería un acto de escritura de carácter melancólico, para reemplazarla por la metáfora de un recorrido por una cámara oscura poblada de olvido, en donde detalles mínimos, cosas, sensaciones, se revelan sustraídos a la 
indeterminación del olvido. La imagen guarda continuidad con otra metáfora, la de la madriguera en la que los animales guardan la comida para el invierno, y en cuya designación se lee el título de su otra novela sustentada en idéntica concepción de la narración. Según esta metáfora, en el origen de los rescates de la memoria estaría una especie de juego propiciatorio por el cual en el pasado habría acumulado de modo casi instintivo, en "depósitos ocultos", una reserva de sensaciones destinadas a ser redescubiertas por ella misma. En esa especie de juego cifra el mecanismo de la escritura como ejercicio de la memoria, que en su despliegue revela, aun para ella misma, los núcleos más recónditos de la intimidad.

Se puede percibir la correspondencia de estos planteos con la idea hoy aceptada como evidencia dentro de la Psicología Social y de la que Maurice Halbwachs es pionero, según la cual la reconstrucción del pasado es posible a partir de significaciones producidas por situaciones presentes. Las condiciones sociales rigen el funcionamiento de la memoria y establecen el carácter social de cualquier tipo de recuerdo. Al mismo tiempo se percibe en la experiencia autobiográfica de la autora el lazo entre memoria y acción, en cuyo segundo término está implicada la escritura: la memoria se despliega por acción de la escritura. Los recuerdos no se conciben como regreso a huellas fijas que están "alli", en el pasado, sino que se construyen al calor del presente de la escritura; esta escritura indaga a partir de núcleos de sentido que anidan en situaciones presentes.

La sucesión de los relatos recorre un eje de significación que denominaremos estado de carencia, como definitoria de la condición del exiliado. En ese proceso de construcción de las representaciones adquiere un papel fundamental la memoria corporal, el papel del cuerpo como lugar de inscripción de la experiencia. En el relato los sucesos importan no sólo como hechos físicos sino por la marca que dejan en el cuerpo, en la psiquis y en la conducta, de modo casi inconsciente. Así, por ejemplo, las referencias a esas indicaciones que alguna vez le formularon amigos ya muertos, convertidas en un verdadero código de conducta al que se ve obligada constantemente, en tanto le otorgan sentido a su estar en la realidad. Son anécdotas puntuales, de índole doméstica, como las indicaciones que Mario Usabiaga le hiciera acerca de cómo asar correctamente 
un bife a la plancha. La repetición ritual de esta acción a lo largo de su vida, le devolverá una y otra vez la imagen del amigo muerto fijada en ese gesto con el que lo recupera amorosamente (Mercado, 1998:29). Está también la vinculación entre la ropa y la condición de indigencia vital, señalada de manera explícita: "la indigencia vestimentaria es el objeto en el que con más crudeza se encarnan los términos de la carencia (...) comprar ropa es un mísero expediente para remendar una vida" (Mercado, 1998:34). La búsqueda incesante de la ropa adecuada que pueda cubrirla, proporcionarle "una forma cerrada que la incluya", define para Tununa una imposibilidad esencial, una búsqueda constante de poner fin a un estado de desnudez irremediable, de permanente desamparo. Por ello, el gesto de vestir ropa de muertos tiene el sentido de cubrir la propia carencia con vestimenta cargada de historias. En un movimiento inverso de enajenación extrema, ya no sólo la ropa viene a cubrir una carencia, sino que toda su identidad se define por el cuidado responsable de esa ropa.

Pero no todos los enunciados del libro tienen la misma índole. Las referencias a esta especie de reservorio de experiencias, de sentimientos, de percepciones, que van componiendo fragmentariamente los estados más inasibles de la interioridad, se alterna con la exposición de contenidos marcados por un creciente grado de objetivación de lo narrado, que va desde la composición de una verdadera fenomenología de la extranjería a la narración de pequeñas historias de exiliados. En este recorrido, la memoria parece desplegarse en abanico ostentando diversos grados de lucidez. Si en el primer caso la escritura parece instalarse en un no saber y se constituye en el acto mismo de rememoración, en los otros parece estar guiada por la intención de exponer lo que se ha aprendido, un conocimiento que se ha convertido en teoría o historias guardadas en la memoria, ya disponibles para la evocación.

La fenomenología de la extranjería se diseña en las historias que van hilvanando la gran narración del exilio en donde puede leerse el proceso por el cual el exiliado adquiere la condición de extranjero. "El espacio del extranjero es un tren en marcha, un avión en vuelo, la transición pura que excluye la parada”, dice Julia Kristeva (Kristeva, 1991:16). En una percepción análoga Tununa Mercado caracteriza el tiempo del exilio como un paréntesis en el que se ha suspendido el continuo, "las hojas no caen, el frío no llega, el presente nunca 
pasa a futuro" (Mercado, 1998:21). La ausencia de tiempo, de lugar de pertenencia, la permanente imposibilidad de inserción aparecen como denominador común de la vida en el exilio: las reuniones semanales de los exiliados para debatir cuestiones políticas y compartir experiencias, o las visitas rituales a la casa de León Trotsky para inscribir el destino individual en la memoria monumental del "mayor desterrado" y padre intelectual. En todas estas acciones en que se resuelve la rutina del exilio hay un carácter de memoria grupal construida selectivamente como forma de supervivencia. La memoria autobiográfica deviene memoria del grupo; la necesidad de remediar la orfandad los lleva a las mismas prácticas por las cuales refuerzan una identidad común.

Provisoriedad, fragilidad, son otras marcas de la extranjería; son las que caracterizan el modo en que la autora se vincula con los libros, cifrado en movimientos de avance y de retroceso, de olvido de lo leído, de una imposibilidad de dar cuenta del contenido. Sólo lo marginal del texto, la materialidad sonora de las palabras más allá de los conceptos se le entrega en la lectura fascinada de la Fenomenología del espíritu de Hegel, lectura coral practicada en comunidad con el grupo de exiliados, desprovistos de un saber o competencias adecuadas a las exigencias de la obra.

La renuncia a un centro, a un sentido convencional es expresión de la misma marginalidad con que encara toda su vida; la que le impide habitar las casas de las diversas mudanzas de un modo que no sea precario, la que convierte en equivalentes los movimientos de ida y de vuelta de cada exilio, expresados en el desorden cronológico de las referencias a sus distintas instancias; porque la condición de extranjero es irreversible, partir y regresar de uno u otro exilio son meros avatares de un destierro que es permanente. Estar de vuelta no es haber regresado, la ajenidad permanece en la imposibilidad de recuperación de la propia ciudad, cuyos lugares más familiares y más añorados durante el exilio, se le vuelven extraños en el recorrido de reconocimiento.

\subsection{Arte poética}


En En estado de memoria hay una dimensión que puede traducirse como meditación sobre el arte. El hilo conductor del relato como narración de la experiencia de extranjería deviene reflexión sobre la propia actividad de escritura, sobre su condición de artista, propiciando una lectura que indica una continuidad entre los contenidos de la experiencia, la memoria, la escritura.

En "Cuerpo de pobre", al referirse a los contenidos que debería explicarle a un hipotético analista, su obsesión por la minucia, por guardar e imponer a los demás una vigilancia inclaudicable sobre los tiempos de cocción del arroz o de la carne, la fobia a sobrepasar los puntos exactos, los razona como índices de una obsesión que ya no sólo se refiere a asuntos domésticos, sino que delatan la persecución de una forma. "No culminar entonces, dejar a medias, dar a las cosas el margen de maduración, incidir sólo en las etapas iniciales de la evolución de un elemento y luego dejarlo abandonado a su propia inercia, no precipitarlo ni cerrarlo, eran las leyes de esa obsesión que colmaba todas mis intenciones y definía todos mis deseos." (Mercado, 1998:32), bien puede ser leído como la explicitación de su arte poética, su tratado de retórica personal.

Este carácter obsesivo y minucioso de su escritura remite a la definición de Benjamin sobre la narración como forma artesanal de la comunicación, producto de esfuerzos duraderos propios del trabajo del artesano, que se demora en los detalles y que en la narración perfecta se traduce en una lenta acumulación de capas de sentido (Benjamín, 1936). En este caso, el punto de partida es la evocación de estados interiores marcada por una condición de extranjería en cuanto al distanciamiento elegido como dispositivo para pensarse. El resultado es una escritura caracterizada por la voluntad de transmitir una experiencia intransferible, por la búsqueda obsesiva de una claridad siempre imposible, por la insistencia en la expresión que traduzca mejor las impresiones. Los relatos titulados "Celdillas" y "La especie furtiva" son una indagación por medio de la escritura del origen del horror y del desvalimiento. En ambos rescata una imagen fundante vinculada con la muerte. En "Celdillas", la percepción angustiosa de la realidad se remonta a una imagen fotográfica de cadáveres en un campo de concentración, guardada por sus padres. En "La especie furtiva", una voz interior desdoblada le anuncia en una revelación fugaz e irrepetible que la muerte está detrás de toda experiencia. Podría decirse que éste es el núcleo de su 
experiencia del arte, el que mueve su necesidad de escritura. Las palabras parecen responder a la necesidad de indagar en las zonas fronterizas de la conciencia buscando infructuosamente dar nombre a lo que podría ser objeto de psicoanálisis, la imagen perturbadora que está en el origen de su sentimiento de deshabitación del mundo. En ese intento, el lenguaje intensifica su prestigio produciendo una enunciación personal, que Deleuze y Guattari caracterizan como desterritorializado, un estar en la propia lengua como extranjero (Deleuze y Guattari, 1975).

Por otra parte, el texto provee una definición explícita de la escritura literaria, a partir de la recurrida analogía entre tejer y escribir. La significación cristalizada que aporta tal imagen es superada creativamente por Mercado, al sostenerla con nuevos argumentos: tejer y escribir, dice, suponen para la persona que realiza tales tareas, un distanciamiento de la realidad, un abstraerse que vuelve a la tela y a la escritura ajenas a cuanto se ve, se huele o se oye: función no mimética en la definición del arte. Pero mientras en la fuga textil hay felicidad, en la del texto sólo se recoge desventura. El arte es una empresa riesgosa porque al mismo tiempo que conduce al sitio del Espíritu, enfrenta a la experiencia de la desnudez fundamental.

3. Escritura como portavoz. Prestar el cuerpo para que el ausente hable

Me propongo leer en Yo nunca te prometí la eternidad de Tununa Mercado (Mercado, 2005) el modo en que se traman las nociones de cuerpo y de escritura. Qué representaciones del cuerpo se juegan en las experiencias traumáticas que narra, entendiendo el cuerpo como entidad en donde se registran las operaciones de vaciamiento y de pérdida que sufren las personas arrojadas a las contingencias del exilio, la expulsión, el exterminio. Hay una primera escritura, la del cuaderno de notas de la protagonista, Sonia, que recoge fragmentariamente esa experiencia y convoca por necesidad de existencia otra voz que le preste cuerpo, que le dé existencia en el cuerpo de otra escritura, la de la narradora, que acepta ese legado mediado por circunstancias azarosas. 
La historia que narra Mercado tiene como núcleo originario un episodio traumático, una escena escuchada al pasar en una conversación, la historia del extravío de Sonia y de su hijo Pierre de seis años, en la primavera europea del cuarenta, durante la huida desde París hacia el sur de Francia, en el contexto de la guerra y de la ocupación alemana. La historia referida es una de tantas historias de desterrados de distintas procedencias que intercambian experiencias en otro exilio, historias ajenas que tejen con las propias la trama del exilio, el de uno y el de todos. La anécdota del niño extraviado tiene una primera versión en su libro En estado de memoria antes de expandirse en éste.

Pero es la figura de Sonia la que nutre y da cuerpo al relato, que se configura desde una concepción fantasmal de la escritura. Es la muerta la que incita a ser narrada y a ser rescatada en la materialización de la escritura, gobernada por esa presencia espectral: "Ella, la muerta, todavía rescatado su nombre, lo musita en mis oídos (...) en una incitación que sólo podría palparse por este impulso mío de escribirlo: Sonia, y de plegarme, pronunciándolo, al esbozo de persona que el nombre me sugiere al incitarme" (Mercado, 2005:5).

Figura del testigo que regresa de la muerte para dar testimonio, el espectro es la entidad que otorga autoridad al relato, que toma la forma de un oráculo convocante: "Ella emerge, como los vapores de una respiración entrecortada, y los vahos que expulsa ese humus de persona, cuando los fuegos se extinguen en mi noche-antesala del contar, tienen una insólita transparencia (...) Como en los encierros de una pesadilla, caminar por la maraña, abrirse paso, regresar..." (6).

La autorreflexión discursiva da cuenta de la laboriosidad concentrada que signa la tarea: las imágenes que describen la materialización de la escritura sugieren que para que nazca el referente evocado se necesita la misma dedicación paciente que requiere el encendido del fuego: "de crecimiento imprevisible", "las piezas buscan ensamblarse", "iluminan de pronto todo el espacio mental", "dejarlos en situación de rescoldo para avivarlos después, cuando el impulso de reunirlos comience a ser relato"(6).

La escritura de la que se hace cargo Mercado se construye, sobre todo, a partir de los fragmentos del diario de Sonia, memoria en forma de apuntes manuscritos, apenas esbozados en las circunstancias de la huida, relato 
entrecortado, sin conectores, que se muestra como radiografía que reproduce las condiciones de vida de los tránsfugas. Esa escritura fragmentaria adquiere el carácter de trazo, cuyo emblema es, en términos de Derrida, el lugar del cuadro en donde se aloja cierta verdad de la pintura: el encuadre que, como tal, promueve un tratamiento especial, en tanto por su ubicación intermedia y de borde tiene la función de marcar una diferencia entre el rasgo visible y el fantasma, entre el afuera y el adentro (Derrida, 2001:25). Esos fragmentos desencuadrados de la escritura primera de Sonia parecen exigir un acercamiento propio de esta condición de trazo, "dan trabajo", "hacen trabajar", como dice Derrida refiriéndose al modo de leer esa marca, pero que muy bien puede reconocerse en la actitud que promueven estos escritos, que parecen no querer encuadrarse pero que a la vez quieren decir algo, una verdad. Se podría decir que el espectro de su primera enunciadora habita esa escritura, espectral ella misma, desligada de su dueña, como los zapatos pintados por van Gogh. ${ }^{4}$ El sujeto ausente cuyo nombre vuelve como un fantasma para merodear la escritura abandonada habilita el trabajo de restitución. La labor de escritura de Mercado, que en función de gohst writer realiza la puesta final, puede verse como un acto de atribución, de restitución en donde se deja leer una desviada intención autobiográfica. La restitución establece derecho de propiedad sobre ese escrito, como si dijera "eso me corresponde", es ponerle el propio cuerpo mediante el cuerpo de la propia escritura para darle carnadura a esos retazos despojados, incompletos, fantasmales. La identificación se manifiesta en el regreso a ese sujeto que dice yo, en donde queda implícito que ella es un semejante, que ella le concierne: "Lo que estaba haciendo, escribirla... era responder a su mandato y así la aislaba, la figuraba, la abstraía de un conjunto... para que, existiendo, me dejara existir al escribirla" (Mercado, 2005:56).

El primer núcleo, la historia de la madre y el niño extraviados, se aloja y se expande en otro, el del escape en masa para huir de la amenaza nazi. La

\footnotetext{
${ }^{4}$ Sigo aquí, trazando una analogía, la argumentación desarrollada por Jacques Derrida sobre el acto de atribución, en el capítulo "Restituciones" de La verdad en pintura en donde toma como pretexto un ensayo de Meyer Schapiro, "La naturaleza muerta como objeto personal", que es una crítica a la interpretción de Heidegger sobre los zapatos de van Gogh en El origen de la obra de arte.
} 
transición entre el arraigo y el éxodo transforma las subjetividades mediadas por nuevas leyes de supervivencia. El cuerpo es entonces la entidad donde se mide la operación de arrasamiento de las identidades, que en las nuevas condiciones de exiliados, refugiados, tránsfugas y apátridas se han configurado bajo el signo de la provisoriedad y de la carencia. El cuerpo de Sonia se vuelve registro sensible de los efectos del trauma. La alteración afecta cada órgano, cada parte del cuerpo: "Estaba dividida: sus articulaciones, sus ojeras, la boca del estómago, la garganta al tragar, allí repercutían Ro y Pierrot; el insomnio repetido, la ansiedad por las noticias que corrían, la inminencia de la llegada hasta ella de los alemanes eran la antesala de una preocupación que diferían la obligación de pensar" (109).

Todo es percibido corporalmente. La masa indiferenciada de los cuerpos en el éxodo borra las trazas individuales, convertidos en bultos que se vuelcan a las carreteras. El pensamiento lúcido de un Walter Benjamín, amigo y ocasional compañero de peregrinaje, es señalado también corporalmente, en contraste con las zonas del cuerpo de Sonia en donde se intensifican las marcas del agotamiento, del hambre y del frío: los pies helados que la martirizan:

...divagaba ella mientras WB en un plano superior de los cuerpos al que la humanidad no llegaba, ejercía un poder de palabra al mismo tiempo perentorio y disolvente, obligándola a pensar (...) El pensamiento de WB, en efecto, quería adueñarse de sus escasos bienes; de su fragilidad, por ejemplo, y de su desesperación de madre y de mujer, y hacer de esa exigua posición una riqueza: que ella pudiera pensar, desde la suela de sus alpargatas hacia arriba, en el destino de la humanidad, más modestamente de Europa y más específicamente de Francia. Costoso esfuerzo pues Sonia no lograba remontar y veía que algo cegaba el espacio de su capacidad de inteligir (...) no la dejaba subir, si pensar es ascender $y$ trascender las circunstancias. (64)

\subsection{La carencia, marca de identidad}

Las condiciones de vida instaladas por el peregrinar abren la noción de frontera, de límite, no sólo en el sentido geográfico sino en el referido a la constitución de la identidad. En principio, el movimiento de expulsión arrebata a los sujetos de sus lugares originarios para instalarlos en un lugar de no retorno, cruce de un límite reconocible en el mapa, a partir del cual no hay un después ni 
un destino prefijado, sólo un continuo de pasos, una marcha hacia lo desconocido. La noción de límite, y más que de límite, de borde, aparece también configurando identidades fluctuantes, resistentes a categorizaciones firmes, instaladas por los avatares de la persecución y de la guerra. ${ }^{5}$ Las versiones de los nombres se multiplican según los lugares de instalación transitoria de la familia: Peter en alemán, será Pierre en Francia durante la vida de refugiados y Pedro en el exilio mexicano. El apellido alemán Preuss deviene Preux en la pronunciación francesa. Sonia, la madre de Pedro, toma ese nombre como nombre de guerra en el contexto de su militancia antifascista, y su verdadero nombre, Charlotte, provoca rechazo en el hijo porque "enajena la identidad misma de su madre, la que él acepta y la que ella aceptó como Sonia" (150). ${ }^{6}$ El ocultamiento de la identidad para poder sobrevivir, percibida como límite radical por el niño Pierre en la temprana recomendación de su madre, "no digas nunca que eres judío", el borramiento de nombres y de patrias, habilitan versiones contradictorias de la vida, verdades que al rodar se transforman y contaminan, que necesitan ser "aceptadas", fijadas, legitimadas, identidades sujetas a atribuciones, según los puntos de vista de cada testimonio. (158) En ese contexto, el cuerpo ofrece un lugar de anclaje donde reconocerse, bajo la forma de lo somático que se transmite por herencia, pero también como una percepción que sólo surge de asociaciones que establece la memoria, como la intuición de Pedro de su pertenencia a una serie, a un linaje de artistas malogrados: el temblequeo de sus manos que le impiden terminar un grabado, se le presenta vinculado al destino "somático" de Ro, su padre, pianista frustrado por haberse quebrado las muñecas y al de Sonia, su madre, que debe suspender sus esculturas en terracota a causa de una artritis (149).

La desposesión se revela como marca extrema de la identidad. Cuando Jean-Luc Nancy reflexiona sobre la ambigüedad cambiante de los puntos de referencia de sí, propone que la identidad subjetiva se resuelve en primer lugar en lo orgánico y remite más específicamente a una carencia. Es aquello que "falta" lo

\footnotetext{
${ }^{5}$ El título elegido para la novela alude precisamente a la experiencia de desposesión y de provisoriedad que instala el exilio, núcleo de la historia narrada, cuya cifra es lo aleatorio, forma resistente a cualquier modo de arraigo o de eternidad.

${ }^{6}$ Destacado mío.
} 
que se presenta con la ajenidad del intruso y promueve el acto de afirmarme en eso que, faltándome, me constituye. ${ }^{7}$ Así, la condición de judía de Sonia, durante la travesía del éxodo, se delata en la carencia de máscaras antigas, que se le niega por extranjera; el ocultamiento de papeles identificatorios esconde una identidad de origen confuso por la rectificación de fronteras en los mapas; negar su derecho a la lengua alemana se vuelve condición de supervivencia. El no tener, termina siendo condición de ser. La carencia y la contingencia la definen en la desposesión: "Era una exiliada de sí misma, una exiliada esencial, para decirlo de algún modo, que sólo reconocía como algo propio la necesidad... Quedarse con lo puesto decía bien de su estado de extranjería de sí misma" (66).

Escribir adquiere en ese contexto el valor de último refugio de la existencia. Frente a la carencia absoluta, la materialidad de la escritura es la forma posible de la trascendencia. Sonia escribe obstinadamente, venciendo el cansancio, el hambre y el agotamiento, como un modo de preservar su singularidad en medio de la multitud que los hace descender a la condición de bultos. La escritura representa "ese orden en el que se protegía" (107) y al mismo tiempo es la garantía de que los altibajos del desplazamiento sólo tienen realidad porque alguien los registra.

La identificación de Tununa Mercado, en función de narradora, con Sonia se insinúa en el juego constante de espejos que propone la escritura al alternar fragmentos en crudo del diario de Sonia, incompleto y entrecortado, con los fragmentos narrados por Mercado que regeneran la trama de los mismos sucesos. La empatía se percibe en la narración focalizada en Sonia de modo que las expresiones resultan atribuibles no sólo a la protagonista sino también a la autora, por ejemplo en la consideración del valor trascendente de la escritura: "Escribir no responde sólo a un afán testimonial... Ella se relee, como si buscara en ese 'calendario' las huellas de un camino que tendrá que seguir, como si sólo

\footnotetext{
7 Jean-Luc Nancy (2006) pone en tensión las nociones de "extranjero" y de "intruso" y propone practicar la ajenidad como actitud en la reflexión sobre la identidad. El acto de transplante de corazón que le ha tocado sobrellevar lo lleva a poner en cuestión la identidad subjetiva, en donde se juegan sin distinción lo orgánico, lo simbólico y lo imaginario. El vacío que deja la ablación del corazón le provoca que repare en el órgano, que se le vuelva ajeno y punto de apoyo de la reflexión sobre sí.
} 
mirándolas hacia atrás, en lo ya transcurrido, pudiera encontrar el modo de romper con la incertidumbre" (106).

También se advierte la empatía en el trabajo de inferencia que realiza Mercado en su reescritura, por la cual reasigna importancia y reconstruye el peso de las escenas apenas sugeridas en las escuetas anotaciones del diario o en algunas palabras usadas por Sonia. ${ }^{8}$

Hasta que, finalmente, la equiparación entre la autora y la protagonista se hace explícita al enunciar las razones de la escritura de esta historia entendida como "la búsqueda de Sonia": la primera vez que ve el diario de Sonia piensa en traducirlo para sus nietas. Pero reconoce que se deja ganar por el deseo de "apropiarme de ese texto, y para disimular, hacía una donación, yo, testaferro de mí misma". Aparece entonces, junto con el desvarío de llenar los blancos, el propósito...

...de devolver, no ya a las nietas, sino a la propia Sonia, algo, un préstamo, un adelanto, que me habría dado y yo había aceptado... Yo, deudora, he seguido alimentando las necesidades de esa mujer, buscándola y buscando todo aquello que compensara su desintegración, alimentando mis propios enormes vacíos, equilibrando con mi búsqueda el desamparo absoluto que la llevó a decidir su vida y su muerte. (183)

\subsection{Límites de la escritura. Narrar desde los márgenes}

Desde una perspectiva psicoanalítica, la de Sonia es una escritura provisoria, en suspenso, no sólo porque supone la muerte, la desaparición de su autor, sino porque lo traumático pone límites a la escritura. Lo público y lo privado como espacios en donde los sujetos se transforman, se han visto alterados y se

\footnotetext{
${ }^{8}$ Se puede percibir al leer las páginas 126 y 127 la actitud de identificación de T. Mercado con la escena sugerida en el cuaderno de Sonia, en la interpretación que realiza a partir de ciertos vocablos empleados por la protagonista cuando describe a quienes la acompañan ocasionalmente: "el compañero católico insinúa afecto, así como el diminutivo soldadito belga reitera el agradecimiento que le suscitó otro soldado... y si acongoja su aparición anónima es porque ellos tuvieron a Sonia... porque ellos oyeron su respiración en la noche y le dieron calor cuando dormía." (destacado en el texto).
} 
prestan para representar dramáticamente las encrucijadas de esos sujetos que transitan en los límites. Teodoro Lecman afirma que lo que no puede ser dicho encuentra las fronteras de su traductibilidad, se mantiene como "letre en souffrance" (letra en espera) y como "l'être en souffrance" (verdadero ser en sufrimiento) (Lecman, 1998) La voz narradora de Tununa Mercado toma esa escritura en suspenso y se aboca al trabajo de reponer las circunstancias de esos sujetos marcados por las miserias de la guerra y de la condición humana. Al dar forma al discurso, presta su voz a la voz enmudecida que pide ser escuchada. Se pone en las circunstancias y en la cultura del momento haciendo que su novelar exceda lo individual. Ambas escrituras, la de Sonia y la de la narradora, expresan este ejercicio de ausencia y presencia: el propio cuerpo se ausenta cuando la escritura se emancipa y adquiere su propio cuerpo y, al mismo tiempo, en el acto de escribir, ese cuerpo escribe el cuerpo y la voz de los otros, según el presupuesto de que aun en lo autobiográfico la escritura moldea el bios para hacerlo auto y heterográfico al mismo tiempo.

La idea que expresa Derrida acerca de que la ausencia es constitutiva de la escritura da lugar al planteo acerca de la ubicación marginal que la literatura elige por necesidad. En efecto, por un lado tenemos el planteo derridiano sobre la potencialidad que define a la escritura: un signo escrito es una marca que permanece, que no se agota en el presente de su inscripción: "Para que un escrito sea escrito es necesario que siga funcionando y siendo legible incluso si lo que se llama el autor del escrito, no responde ya de lo que ha escrito, de lo que parece haber firmado, ya esté ausente provisionalmente, ya esté muerto" (Derrida, 1998:347). Es esa ausencia radical lo que hace funcionar la escritura de Sonia y lo que la constituye como el lugar en donde habita su fantasma. Iterabilidad de la escritura que pervive más allá de la presencia de un destinatario y de un enunciador. Pero por otro lado, sólo en los márgenes esa inscripción encuentra el medio propicio para volverse voz audible, para activarse como escritura. La escritura literaria de Tununa Mercado, protagonizando la interrogación desde "la otra cara del mundo" construye "un relato en condicional", "un relato que deja ver las partes sustanciales de la historia desde otro lado", un relato posible. (Mercado, 2005:150). Narrar desde otro lado parece ser el imperativo si se quiere "hacer visible e inteligible la materia" (148), para prestar 
voz a esos restos que testimonian la ausencia de los protagonistas. Los fragmentos autorreflexivos que dan cuenta del trámite de investigación previo a la escritura sugieren esa idea:

\footnotetext{
Y tanto debió resultarle insólita mi presencia, pese a que Pedro le había anticipado que iría a verlo porque estaba escribiendo un libro sobre Sonia, que me conminó Who are you? (...) Los implícitos eran comprensibles: osadía de extranjera, objetivos extraños surgidos de un mundo tan distante de él por lengua y cultura como podrían serlo para mí el hebreo o el judaísmo en Israel. (148)
}

La funcionalidad de esta perspectiva nacida en los márgenes parece ser eco de las reflexiones de Walter Mignolo sobre la colonialidad del conocimiento, sobre la reivindicación de una legitimidad del conocimiento cuya enunciación se produce en las zonas desplazadas de los centros de poder instaurados por la modernidad (Mignolo, 2002). Desde esta perspectiva, la palabra que se genera en otras fuentes, que bebe en otras aguas, la palabra de Mercado que vive su propia experiencia del exilio en México obtiene validez en la virtud de operar una transformación de la historia original conservada en suspenso, al encontrar el modo de hacerla decantar en un relato que es a la vez hetero y homodiegético. Narrar desde las lindes, esto es, prestar vehículo al relato desde la mirada ajena. El bosque del Ajusco aparece como emblema del lugar desplazado que la historia encuentra para arraigar en la experiencia personal de la narradora:

\begin{abstract}
Ella, sin embargo, quiere estar, y por la insistencia con que se me impone está diciéndome que por un azar de destinos sólo en mi bosque - ese Ajusco que ha aparecido sin anuncios como cementerio de Aire, así como otros espacios, el Río de la Plata o el Océano Atlántico, lo son de Agua, y estos dos últimos incluso lo serán de Agua y Aire-, (...) sólo en mi bosque, decía, puede inhalar y exhalar, aspirar y expirar, siendo este último verbo, en la secuencia que la incluye como persona, eufemismo del morir. (Mercado, 2005:6)
\end{abstract}

\title{
3.3. La narradora anatomista exhibe la carne de la escritura
}

La corporalidad de la escritura se expone de modo explícito en la exhibición de fragmentos de escritos documentales que la autora ha tenido en sus 
manos y ha considerado como fuentes de la historia. Como recurso, su aporte intercalado en el cuerpo de la novela parece distanciarse del que practica Puig, en donde la sucesión de textos-documentos van construyendo el relato por yuxtaposición. Aquí, en cambio, la mostración del archivo parece tener el sentido de la mostración de los cuerpos de escritura que la narradora exhibe, en analogía con la labor del anatomista, aquel que en los albores de la modernidad practica la espectacularización del cadáver, motivado por la curiosidad de conocer aquello incognoscible del individuo. ${ }^{9}$ La consideración es particularmente pertinente, más que para los diferentes fragmentos del diario y el relato inconcluso de Sonia, para dos conjuntos de cartas escritas por la protagonista, unas correspondientes a los comienzos del exilio en México en la década del cuarenta, dirigidas a su hermano, las otras, a fines de los años cincuenta, dirigidas a su madre. La presentación va acompañada de consideraciones de la narradora acerca del cuidado que ha tenido con el material en pos de preservar su valor en tanto cuerpo evidente que expone un saber. Narradora anatomista que en la carne de la escritura enseña el saber del que se nutre el organismo de la escritura literaria.

No he tocado las primeras dirigidas a Hanán (...) (aunque) su legibilidad estaba condicionada por el papel en el que fueron escritas y por el tiempo que suele adelgazar los materiales hasta casi extinguirlos. El segundo paquete sufrió algún recorte. Son las cartas de Sonia a su madre (...) Fueron traducidas del inglés y del alemán, lo cual en gran medida supone alguna cuota de tergiversación. (276)

Pero en el camino, el rol de la anatomista se tensiona con el de la artista. Los fragmentos encuentran en el régimen de la escritura literaria de Mercado la modulación que les devuelve la forma humanizada. No son fragmentos inertes los que se muestran sino que en sus resonancias afectivas, alienta la persona de Sonia, traducida en las emociones que marcan la conversación con su madre y con el hermano, las angustias con que tramita el ingreso de su madre como

\footnotetext{
${ }^{9}$ Véase David Le Bretón (1990), Antropología del cuerpo y modernidad. Afirma que estudiar las relaciones entre cuerpo y modernidad es estudiar el proceso de individuación en la trama social, el camino que lleva a romper la solidaridad entre persona y colectividad. Analiza, a lo largo de la historia, formas de resistencia al concepto de individuo instalado desde la modernidad.
} 
refugiada, su nostalgia y su amor por París, sus apreciaciones sobre los avatares de la vida cotidiana, la salud, el clima, las demoras del correo.

El afán memorialista que subyace detrás de la tarea escrituraria de Mercado corresponde, según la autora, al género del álbum (256). Colección de imágenes atesoradas como piezas que construyen el contar, en este caso tienen como origen historias ajenas. Nacido como acto privado, íntimo, doméstico, el álbum se sostiene sin embargo en el deseo de trascender. Estas reflexiones ponen de relieve la moral que preside el acto de aceptación del legado de Sonia y de la tarea de rescate mediante la escritura, en un proyecto que se hace personal, asumiendo las vías de lo autobiográfico. Las conceptualizaciones de Jean-Luc Nancy vienen al caso para hablar de la actitud presupuesta en el trabajo de restitución del sentido. En $A$ la escucha Nancy se pregunta: ¿Qué significa estar (être) a la escucha como quien dice ser (être) en el mundo? ¿Qué elementos de la experiencia y la verdad se ponen en juego allí? "Escuchar" es un verbo que guarda un doble sentido: usar un órgano sensorial (la oreja, el oído) y una tensión, una atención (aguzar el oído, escuchar atentamente) Escuchar (en francés, entendre) tiene una relación particular con el sentido debido a la doble acepción del verbo en francés. "Entendre" es escuchar y también entender, como si en todo entender hubiera una escucha y en todo decir, un entender. Tal vez el sentido no se conforma sólo con tener sentido (ser logos) sino que además resuena. En la resonancia está la profundidad primera o última del "sentido" mismo (o de la verdad). Esta parece ser la actitud que preside el rescate que la autora realiza de la voz muerta y de la historia heredada. Estar atento a un sentido que siempre está en los márgenes, que siempre es una franja de sentido. Esa convicción trae consecuencias en la retórica y en la ética del "traductor". Por un lado promueve un estilo en el que prima la incompletud, los cambios de foco, la exposición de fragmentos, que vienen a dar cuenta de ese intento de no agotar el sentido, de no imponer una interpretación. Por otro lado la actitud ética tiene que ver con lo que Nancy denomina "tocar sin tocar", no apropiarme del otro que es mi límite, el otro es otro cuerpo que constituye mi límite. Actitud de pudor, ética de la escritura que habla del respeto por el otro en el respeto por el sentido, que nunca se entrega totalmente. 


\section{Bibliografía}

Agamben, G. (1996): "Política del exilio", en Archipiélago. Cuadernos de crítica de la cultura, № 26-27. Paidós, Barcelona.

Benjamin, W. (1936): "El narrador", en lluminaciones IV. Santillana, Madrid, 1998.

Blanchot, M. (1955): El espacio literario, $2^{a}$ ed. Paidós, Barcelona, 1992.

Deleuze, G. y Guattari, F. (1975): Kafka. Por una literatura menor. México, Era, 1998.

Derrida, J. (1998): "Firma acontecimiento, contexto", en Márgenes de la filosofía.

Cátedra, Madrid.

(2001): La verdad en pintura. Paidós, Buenos Aires.

Halbwachs, M. (1925): Les cadres sociaux de la mémoire. Albin Michel, Paris, 1994.

(1941): La topographie légendaire des Évangiles en Terre Sainte. PUF, Paris, 1971.

(1950): La mémoire collective, PUF, Paris, 1968.

Jodelet, D. (1993): "El lado moral y afectivo de la historia. Un ejemplo de memoria de masas: el proceso a K. Barbie, 'el carnicero de Lyon'”, en Psicología Política № 6. 53-72.

(1986): "Loco y locura en un medio rural francés: una aproximación monográfica", en $L^{\prime}$ étude des representations sociales, W. Doise et A. Palmonari, (ed.). Delachaux et Niestlé, Paris. (Traducción de Fátima Flores P., México, 1995).

(1991): "Representaciones sociales: un área en expansión”, en Sida, imagen y prevención, D. Páez (ed.). Fundamentos, Madrid.

Kristeva, J. (1991): Extranjeros para nosotros mismos. Plaza y Janes, Barcelona.

Le Bretón, D. (1990): Antropología del cuerpo y modernidad. Nueva Visión, Buenos Aires.

Lecman, T. (1998): Cuerpo y símbolo, Lugar, Buenos Aires.

Martínez_Richter, M. (1997): La caja de la escritura. Diálogos con narradores y críticos argentinos. Iberoamericana, Madrid.

Mercado, T. (1990): En estado de memoria, $2^{\mathrm{a}}$ ed. Alción, Córdoba, 1998.

(2005): Yo nunca te prometí la eternidad. Planeta, Buenos Aires. 
Mignolo, W. (2002): Diseños globales e Historias locales: colonialidad, conocimiento subalterno y pensamiento fronterizo. Duke, Madrid.

Nancy, J. L. (2007): A la escucha. Amorrortu, Buenos Aires.

(2006): El intruso. Amorrortu, Buenos Aires-Madrid.

Pichón Riviere, M.: "Desventuras y peligros de los escritos íntimos", en Clarín, Cultura y Nación, jueves 7 de mayo de 1998, 2.

Schuman, H.; Belli, R.; Bischoping, K.: "La base generacional del conocimiento histórico", en Memorias colectivas de procesos culturales y políticos, Páez y otros, Universidad del País Vasco.

Walsh, C.: Entrevista a Walter Mignolo, "Las geopolíticas del conocimiento y colonialidad del poder". 